\title{
Ethics in Public Administration in Kosovo
}

\author{
Azem Duraku \\ PhD Cand. Departament of Finance, \\ Faculty of Economy, University of Tirana, Albania
}

\begin{abstract}
It is important for the state to maintain and increase public confidence in the Public Administration. This trust grows and is kept in public only when civil servants, officials, perform duties with integrity, impartiality and fairness. Ethics is being discussed very recently and it is becoming an extremely mention topic for the business, public administration and in social private environments. Unethical and corrupt behaviour can not only be prevented by punitive measures, from inside and outside analysis, it has a negative perception on corruption in state institutions. Every day in the media, we can encounter information about the bad behaviour of public administration officials regarding corruption, Kosovo is ranked in unsatisfactory positions regarding this phenomenon. It is important to prepare the self-public manual institution guide, which should rely on international standards and policy implementation in practice. The question is whether only legal and sublegal acts are enough to keep this problem under control ? In this paper we will study the legislation, covering the field of ethical behaviour and good practices of combating these negative phenomena.
\end{abstract}

Keywords: Ethics, The code of conduct, Integrity, Public officials, Public administration.

\section{Introduction}

Every day in the media, but also in our work, we can find information about the misconduct of public administration officials, as well as various corruption-related studies or rankings; Kosovo is ranked in unsatisfactory positions regarding this phenomenon. Will it be analysed in terms of legislation, ethics and corruption, are they regulated, in public institutions? Do they have internal regulations and action plans for maintaining integrity? Are the designed plans enough? Legal Infrastructure and Anti-Corruption Plans are just one step towards achieving the goal of fighting corruption and preventing unethical behaviour, while the main part of prevention of negative phenomena remains the education of employees, training of officials and taking criminal-administrative actions by competent bodies for offenders. In this paper there will be recommendations aimed at combating corruption and promoting ethical behaviours in public administration.

The paper combines the method of conceptual elaboration of the most important issues of the law and other guidelines in such a way as to become guide examples to public officials.

In these works will be studied issues related to: Ethics in public administration; ethical decision making; the concept of integrity and state integrity system; understanding the role and accountability of public officials towards increasing the perception of the public; transparency in the Public Administration; solving different situations for the conflict of interest.

\section{Research Methodology}

The work was done based on the research in the area of ethics in Public Administration which deals with and analyses with particular emphasis issues of this field, the regulation applicable to the rules of this field. During this research I have used the notes, data and publications from the official websites of the Ministry of Public Administration, Tax Administration, Corruption Agency, and other relevant institutions.

\section{The meaning of Ethics in Public Administration}

Life in the civil service, the public wants to walk on the road that foretell the written and unwritten principles of good manners. The term ethics in everyday life is encountered in many spheres of life such as professional ethics, ethics, business ethics, political ethics, etc., but by defining the notion of ethics, we try to elaborate ethics in public administration. The life of being a civil servant, public, differs from the life of being student, student, employee, businessman, politician, etc. and the higher 
the level of education and occupation, the higher the responsibility for the public, and the higher the consequences for the person who behaves in an unfair way.

Starting from what was said above, the notion of "ethics" is vast and involves not only civil servants, public servants in the public administration but touching the highest personalities of a state to the most simple individuals.

The word ethics stems from the Greek expression "ethos", "ethikos" that implies morality. It has the meaning of tradition, doctrine and habits.

Ethics is a system of moral principles or a behavioural code of social groups, religious or civil which clarified the good of evil and the choice of the individual to do what is good.

According to the definition of today's Albanian dictionary, ethics is:

1. Science that studies morality, principles, norms and rules of people's behaviour in society.

2. Morality of a society, of a class, of a social group etc. For example, Professional ethics (scientific).

Ethics can be considered as a study of what is good or right for human beings actions.

\section{Seven Important Points for Ethics}

Ethics is not a new topic for discussion. Ethics has been discussed, debated over thousands of years in all cultures, religions, countries, states, communities and regions of the world. Whether the context is public or private, international or local, at the organizational or private level, the issue of ethics has been and is essential of these raised problems.

Ethics has been to the attention of great thinkers and ordinary people since mankind could distinguish right from wrong. Ethics as a theoretical construct and operational strategy has described the thoughts of Plato, Confettius, Buddha, Muhammad, Jesus, and many others. The values associated with applied ethics are at the heart of the Quran, the Bible, and the respective codes that they should follow. Ethics has been the "stuff" of great artwork for centuries. This means that we are dealing with important ideas, timely tested and highly honoured for centuries.

Ethics or its absence is determined by behaviour or by the so-called "applied ethics" - since as a concept of ethics there is a need for concrete examples. As a result, we use as reference "applied ethics" that refers to the application of values, principles and different standards.

Endless discussions about what is right and wrong, acceptable or unacceptable behaviour in organizations, communities, and society have not banned the need or commitment of mankind to "translate" behavioural norms that are agreed upon in code of ethics or codes of conduct - "right" and "wrong" are highly open terms to various interpretations that often result in confusion. However, these terms are also the main components on which we build ethical notions.

Ethics or its absence in the Organization, but today in the Institutions is a topic that is debated very much. "Transparency International ", which is a coalition against corruption, evolved from a concept into a worldwide operational reality in less than 10 years. Ethics has become a growing industry. The fact that 10 years before Ethics was a non-compulsory subject in Business Schools in the world and today is one of the most studied and compulsory courses in the teaching process, it speaks of the importance of this science.

We may not have anything new to write about ethics or its absence in Organizations, Institutions - so we can refer to existing concepts. Referring to Ludwig Wittgenstein's commentary "... that problems are solved, not by providing new information but by arranging what we have known long ago".

Referring to the last comment, there may still be ways, opportunities and time to "pack" the conventional wisdom that exists around ethics to serve the specific needs of individuals and groups. Because the number of practices where ethics is embodied is among the most, and the ethical judgments that we offer are different, this means that this "ingenuity" is enriched every day.

There are many ethical dilemmas that public officials often face or may face in the life of being civil servants, and these can be grouped into four categories: 
The first type of dilemma that are facing public officials is when none of the options they have are completely satisfactory and should choose the worst or better option compared to the others we have available.

The second type of dilemma is when we have more than one good option or all of the options are good and when we have to choose one. In that case, our venue will result in the rejection of other good options and the public official has to make a choice between "the best options".

The third type of dilemma occurs when a decision that is likely to lead to different effects. From the decision will be satisfy a group of people, while the other group will be dissatisfied. In this case, the option that will satisfy a larger number of people needs to be solved.

The fourth and last type of dilemma occurs when the official has to make a decision, which has a positive or negative effect on the decision maker of the institution or his relatives.

To make sure that the decision cannot be interpreted differently, we must find answers between these questions:

- Is the decision lawful based on legal proceedings?

- Is the decision ethical?

- Is the effective decision?

Rarely, in the above three questions we find many answers, but if we have two or three choices for decision-making we have to decide on the alternative that most responds to the above-mentioned questions.

\section{Code of Conduct for Civil Servants in Kosovo Civil Service}

Part of the process of reforming public administration in Kosovo is the drafting and adoption of the Civil Servant's Code of Civil Procedure, which was approved by the Government of the Republic of Kosovo. The Code of Conduct for Civil Servants is the integrity of the principles and norms on the basis of which all civil servants and other staff engaged in state institutions will act. The Code of Conduct for Civil Servants aims to establish behavioural rules for civil servants and other staff engaged, protect their status as well as regulating the rights and duties of civil servants in relation to institutions and citizens in accordance with the legislation in force.

The purpose of the Code of Conduct is to promote the quality of public services for citizens, ethics in work and the public interest, characterized by integrity, honesty, objectivity and impartiality in fulfilling their duties and other staff engaged:

The Principle of Legality;

The Principle of Non-Discrimination;

The obligation to respond the requests;

Efficiency and effectiveness;

Responsibility;

Impartiality and professional independence;

Transparent ;

Avoiding conflict of interest;

Principle of Equal Opportunities for Communities and Gender;

The key goals of the Code to Conduct are:

Defining the rules of civil servants reception,

protection of the status employees and other staff, regulating their rights and obligations in relation to the citizens and the institution.

In addition, the code is based on the principles in which civil servants work on: legality, non-discrimination, political neutrality, impartiality and transparency in the fulfilment of their duties. 
Non-formal economy at the global level1 is estimated to be equal to $33 \%$ of GDP Global. In EU2 ${ }^{1}$, the average size was $18.5 \%$ in 2012. Recently the macroeconomic calculations regarding the informal economy in Kosovo are from 2007. The team of an EU project ${ }^{2}$ has estimated that the rate of the informal economy in Kosovo during 2004-2006 was 26.67 - 34.75\% of Kosovo's GDP. In absolute terms is varied between EUR 605000000 and EUR 793000000 per year. However, the same level of the informal economy meant an absolute value between EUR 1,312,678,800 and EUR 1,691,241,600 in $2012^{3}$. A study involving companies was conducted in Kosovo in 2013 to assess the degree of informal economy. ${ }^{4}$ The end of this study was $34.4 \%$ of GDP.

The level of informal economy in Kosovo is estimated to be at the same level as in other Western Balkan countries. The rate of informal economy in neighbouring Kosovo varies between $23-38.8 \%$ of GDP.

\section{Conflict of interest and its types}

Conflict of interest has become a global issue in both the public and private sectors and requires institutional treatment as required by the law and practices of developed countries.

We are aware that the conflict of interest cannot be prevented by punitive measures only, although numerous efforts have been made in Kosovo to prevent this phenomenon, such as through legislation, workshops, trainings. We come across information on day to day basis, both in media and in our work, that officials with or without knowledge fall into situations of conflict of interest.

Therefore, a conflict of interest situation can be at present, or it can be ascertained that it existed at a given time in the past. Conversely, it can be said that there is a visible conflict of interest when an official's private interests might erroneously affect the performance of their duties but in fact it is not the case.

A potential conflict arises where a public official has a private interests that are as such that a conflict of interest may arise, if the official becomes involved in an official (conflicting) responsibility in future.

Where a private interest has in fact compromised the proper performance of public duties, that specific situation is rather considered as a case of misconduct or 'abuse of duties' or even corruption, rather than a 'conflict of interest'. In this definition, 'private interests' are not limited to financial, monetary or interest generating a direct personal benefit to the public official.

Subject to legislation governing the issue of conflict of interest, civil servant, once employed or appointed, are obliged to refrain from any activity that leads to conflict of interest. The Law on Conflict of Interest but also the Civil Servants Code of Conduct as well as certain guidelines of the institutions define the personal and private interests.

Conflict of interest occurs in various forms, where among the most important are the following:

Exercise of influence - occurs when a civil servant tries to influence a decision in favor of a third party in which the servant has a particular interest. For example, when a senior decision-maker rightly issues an order to carry out a work where his private enterprise makes a significant contribution

Misuse of Information - This is where officials use official information that is not open to the general public and they use it for their personal purposes.

Bribery - This is the unlawful acceptance of money or other valuables, benefit of various favours by civil servants who use their official positions. In general, bribery relates to money, but may also include other benefits such as sexual favors, promises of favourable publicity, or bids to become a member of exclusive social circles.

\footnotetext{
1 European Platform to increase European co-operation in preventing and stopping unspecified work, European Commission Roadmap, $04 / 2013$.

2 Study on the Scale and Prevention of Informal Economy and Money Laundering in Kosovo,

EU Project 05KOS01 / 03/03/001, 2007

${ }^{3}$ Kosovo Gross Domestic Product, Kosovo Agency of Statistics, 2013.

${ }^{4}$ Business Perspectives of Informality in Kosovo Friedrich Ebert Stiftung and Kosovo Foundation for Kosovo

Open Society and Riinvest Institute for Research and Development, 2013.
} 
Financial Transactions - are about those cases where the civil servant has direct or indirect financial interests that directly conflict with the performance of the work performed. E.g. The Planning Director builds an airport in a place where he has private property and not elsewhere where it could be more convenient for citizens. The choice of place is made to pursue his private interests.

Gifts and entertainment - acceptance of gifts or "hospitality" create conflict if they affect the impartial performance of the duties by a servant. These include low priced purchases, theatre tickets, holidays, sexual favours, improper use of vehicles, equipment etc.

External employment - Part-time employment, consultancy, may cause a conflict of interest with official duties. We have a conflict when it comes to jobs that are related to mutual interests. For unrelated jobs, we do not have a conflict of interest, but we may have activities that conflict with the nature of the job.

Future Employment - If an employee of the Public Administration performs an action today in favour of a third party in order to start working at the entity, to which it has done the favour, after finishing the working hours, then we are dealing with Conflict of Interest.

Relationships with Relatives - Situations when a civil servant can make favours to a relative, constitutes a conflict per se. This kind of conflict may have roots in uneconomic interests.

\section{Types of the conflict of interest}

For the purpose of this paper we will address the following types of conflict of interest.

Potential conflict of interest;

Perceived or apparent conflict of interest ;

Factual or actual conflict of interest;

Continuing conflict of interest;

Case by case conflict of interest.

Potential conflict of interest, occurs in a situation or situations in which the private interests of the official may present a future conflict of interest or apparent conflict of interest if the official is involved in certain duties and responsibilities. This type of conflict of interest needs to be monitored by the institution and prevented, if we manage to establish mechanisms of self-declaration or detection before they occur.

Perceived or apparent conflict of interest, is a situation in which the private interests of the official appear in appearance or form, as if they have influenced or may influence the improper conduct of his official duties or responsibilities, but in reality the influence does not occur, it cannot happen or it is unlikely to happen. A perceived conflict of interest may exist when a third party can form the view that a person's private interest may unlawfully influence the performance of their duties now or in the future.

Factual or actual conflict of interest is a situation in which the private interests of the official influence, have influenced or may influence the unfair conduct of his official duties or responsibilities;

A factual conflict of interest is the situation where there is a factual conflict between a person's public duties and his private interests (e.g. an official votes himself to be a board member in a public company). According to the meaning of the case by case factual conflict of interest, we are dealing with a conflict that is occurring, has occurred, as a result of a decisionmaking that has already taken effect, it may have occurred in a decision-making that has already taken effect.

Continuing conflict of interest The continuing conflict of interest is when conflict of interest occurs repeatedly when conflicts of interest arise frequently.

Case by case conflict of interest, is a situation of conflict of interest that occurs case by case and relates to a particular decision-making. It is a situation of conflict of interest in one of three types: Factual, Potential and Perceived conflict of interest e.g. the official who has to issue a decision based on the residential plan drafted by his wife should withdraw from 
that case and does not need to quit the job but rather does not participate directly or indirectly in the review and analysis of that case.

To come to a conclusion as to whether or not there is a case-by-case conflict of interest, it is advisable to follow the following methodological steps:

What are the specific and detailed duties and competencies of the official in question?

Does he have a fundamental and decisive competence in decision-making for issuing normative and / or individual concrete acts?

What is the sphere (field, scope) of the impact of this act?

How strong is the impact of this act on this sphere?

What are the private interests of the official in question?

What is the likelihood for this act to influence the private interests of this officer in his favor?

What is the likelihood that the private interests of the official negatively influence on his role in decision-making for this act?

Is there a strong cause-effect relationship between the interests and the act, such that public decision-making may be, for this reason and only to him, an unjust decision-making?

Based on the definitions of case by case conflict of interest and the continuous one, the difference is that the act, by the official, in case by case conflict officer is not repeated, while in the continuing conflict of interest it is repeated.

One of the cases of conflict of interest may occur influencing these factors: the "sake, friendship, revenge, profit, etc.".

Determining the risk level:

This determination is made by combining the assessment of the likelihood of occurrence of the risk and the consequences of the risk presented.

Figure 1. Risk presentation matrix.

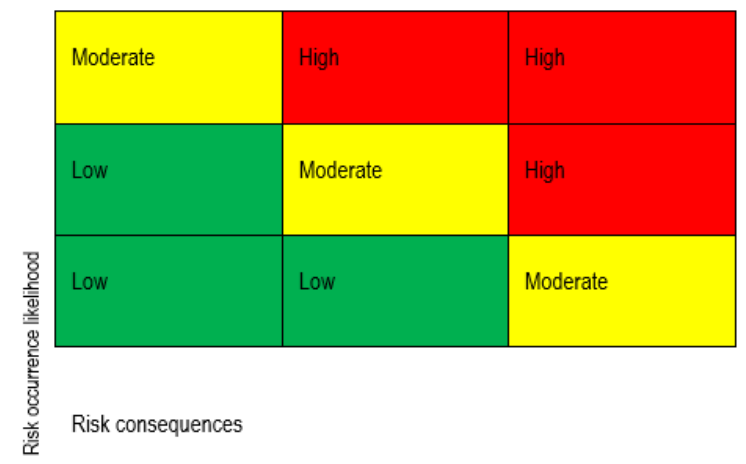

The figure of risk ranked according to the levels of integrity risk enables us to create the integrity plan for the institution.

\section{Conclusions and recommendations}

In the framework of the public administration, the legislation that regulates the norms of conduct is: Code of Conduct for Civil Servants, Law on Civil Servants, Law on Access to Public Documents, Law on Public Procurement, other regulations and internal acts issued by organizations.

No public or private institution may allow the acceptable behaviour in the organization not to be governed through written acts. Personality, culture, behaviours are not a safeguard for the public administration that the official will not make unusual 
actions in particular cases. Therefore, in view of this risk, it is imperative that the institution has clear actions for ethical behaviour. These goals are often summarized and referred to as codes of conduct or ethics.

Codes of ethics increase the certainty of the organization that officials will behave in certain ways according to the guidelines or prohibitions that are contained to that code.

Officials shall respect the rules in part by focusing on the personality of their actions and partly by focusing on sanctions for violations. Additionally, referring to the Code may prevent the motive or self-denial to commit an unethical action.

Codes of ethics can function as a professional statement that expresses public service commitments for a particular set of moral standards. Codes can help ensure that you are a part of civil service. Pride is an important emotion in motivating individuals to see themselves as professionals.

Ethical standards for civil servants should be clear, the public official should know the basic principles and standards expected to apply in his work, and know where the limits of acceptable behaviour are and what behaviours are not acceptable to the organization. The rules of ethics must correspond to the vision and mission of the organization.

There should be clear guidelines for interactions between the private and public sectors. Public life is different from life in the private sector, various pressures that may violate the integrity of the institution. The institution should be prepared to overcome the non-ethical behaviour promoted by the private sector and vice versa.

The Government's budget for financial years 2019 includes national-level targets regarding the prevention of informal economy and the necessary procedures for responsible administrative and law enforcement institutions.

Responsible law enforcement institutions for the prevention of informal economy, conflict of interest and other necessary procedures prepare performance plans. These plans should include precise institutional objectives, measures for their implementation, and key performance indicators related to the prevention of informal economy related to conflicts of interest that may have as a preventative measure. Performance plans' objectives at the institutional level should derive from the Government's budget goals and therefore their drafting should start simultaneously with the government budget for the financial year.

\section{Bibliography and Literature}

[1] HIDAA, (2016): Explanatory Handbook and Prevention of Conflict of Interest Training, Prepared by the High Inspectorate of Declaration and Audit of Assets, Albania;

[2] Carol, S., (2010): Gilman The ethics in Public service.

[3] USAID, 2010): Guide of Administrative investigations of Criminal Offenses of Corruption of Private Interest, Albania.

[4] Law no. 03 / L-149, Law on Civil Service in the Republic of Kosovo.

[5] Law no. 03 / L-159 on the Anti-Corruption Agency.

[6] Law no. 03 / L-215 on Access to Public Documents.

[7] Law No. 04 / L-051, Law on Prevention of Conflict of Interest in the Exercise of Public Functions.

[8] The Code of Conduct for Civil Servants in Kosovo Civil Service No. 01/2006.

[9] Transparency International, (2009): Global Corruption Barometer.

[10] http://dictionary.reference.com/browse/ethics.

[11] http://info.worldbank.org/etools/docs/library/35970/mod03.

[12] http://www.tbs-sct.gc.ca/. 